\title{
PENERAPAN PSAK ADOPSI IAS 41 AGRICULTURE
}

\author{
Stefanus Ariyanto; Heri Sukendar; Heny Kurniawati \\ Accounting and Finance Department, Faculty of Economic and Communication, BINUS University \\ Jln. K.H. Syahdan No.9, Palmerah, Jakarta Barat 11480 \\ stefanus.ariyanto@yahoo.com; heris1024@yahoo.com; kurniawati.heny@gmail.com
}

\begin{abstract}
This study aims to determine whether the application of PSAK adopted from IAS 41: Agriculture should be applied to State-Owned Enterprises, especially the plantation SOE. So that the SOE financial information produced becomes more useful for decision-making. Furthermore, this study wants to answer what benefits can be obtained from the implementation of this standard on the plantation-based SOE. The main characteristic of IAS is the use of fair value model for biological assets owned by the agriculture-based entity. The use of this model raises a lot of controversy, primarily, associated with relevant quality and reliability of the information it produces. Research used qualitative method with data collection through literature study, survey, interview, and observation. Survey and interview were divided into two major parts, which were: on the compilers of financial statements and the stakeholders. From this study it can be concluded that the PSAK based on IAS 41 have not to be implemented yet in the near future due to IAS 41 will undergo quite significant revision. Currently, the StateOwned Enterprises could use the PSAK plantation SOE that has been issued.
\end{abstract}

Keywords: entity, agriculture, finance

\begin{abstract}
ABSTRAK
Penelitian ini bertujuan untuk mengetahui apakah penerapan PSAK yang diadopsi dari IAS 41: Agriculture, perlu diterapkan pada Badan Usaha Milik Negara (BUMN), khususnya BUMN Perkebunan agar informasi keuangan yang dihasilkan menjadi lebih berguna bagi pengambilan keputusan. Lebih jauh penelitian ini ingin menjawab manfaat yang dapat diperoleh atas penerapan PSAK tersebut pada BUMN berbasis Perkebunan. Karakteristik utama dari IAS adalah penggunaan model nilai wajar untuk aktiva biologis yang dimiliki oleh entitas berbasis pertanian. Penggunaan model ini menuai banyak kontroversi terutama terkait kualitas relevan dan keandalan informasi yang dihasilkannya. Metode penelitian berupa metode penelitian kualitatif dengan pengumpulan data melalui studi literatur, survei, interview, dan observasi. Survei dan interview dibagi menjadi dua bagian besar, yaitu pada penyusun laporan keuangan dan pada pemegang kepentingan. Dari penelitian dapat disimpulkan bahwa PSAK yang berbasis IAS 41 belum akan diterapkan dalam waktu dekat ini karena IAS 41 sendiri akan mengalami revisi yang cukup signifikan. Saat ini BUMN perkebunan dapat menggunakan PSAK BUMN Perkebunan yang telah diterbitkan.
\end{abstract}

Kata kunci: entitas, pertanian, keuangan 


\section{PENDAHULUAN}

Indonesia, sebagai salah satu anggota G20, telah ikut serta dalam kesepakatan pemimpin negara G20 di Washington DC, 15 November 2008, mengenai pencanangan prinsip-prinsip G20. Prinsip G20 tersebut kemudian diperdalam dalam pertemuan G20 di London, 2 April 2009, yang salah satunya adalah Strengthening Financial Supervision and Regulation dengan salah satu butirnya berbunyi: “...achieve a single set of high-quality global accounting standards." Berdasarkan kesepakatan tersebut, Ikatan Akuntan Indonesia (IAI) melaksanakan amanat dari Pemerintah RI tersebut dengan melakukan konvergensi standar akuntansi nasional ke standar akuntansi internasional. Standar akuntansi internasional yang dimaksud adalah standar yang dikembangkan oleh International Accounting Standard Board (IASB). Dengan demikian, arah standar akuntansi berubah dari yang semula berkiblat ke United States Generally Accepted Accounting Standard Principle (US GAAP) ke IFRS. Konvergensi IFRS tersebut diharapkan dapat (1) memudahkan pemahaman atas laporan keuangan dengan penggunaan Standar Akuntansi Keuangan yang dikenal secara internasional (enhance comparability); (2) meningkatkan arus investasi global melalui transparansi; (3) menurunkan biaya modal dengan membuka peluang fund raising melalui pasar modal secara global; (4) menciptakan efisiensi penyusunan laporan keuangan.

Untuk dapat mencapai hal-hal yang diharapkan tersebut, Dewan Standar IAI telah menyusun roadmap konvergensi IFRS sebagai berikut. Pertama, tahap adopsi (2008-2010) dengan agenda mengadopsi seluruh IFRS ke PSAK, mempersiapkan infrastruktur yang diperlukan, dan mengevaluasi dan mengelola dampak adopsi terhadap PSAK yang berlaku. Kedua, tahap persiapan akhir (2011) dengan agenda menyelesaikan persiapan infrastruktur yang diperlukan dan menerapkan secara bertahap beberapa PSAK berbasis IFRS. Ketiga, tahap implementasi (2012) dengan agenda menerapkan PSAK berbasis IFRS secara bertahap dan mengevaluasi dampak penerapan PSAK secara komprehensif. Standar akuntansi internasional merupakan satu standar yang diharapkan menjadi standar dengan kualitas andal dan mempunyai banyak manfaat. Salah satu manfaat pentingnya yaitu meningkatkan kemampuan daya banding laporan keuangan terutama laporan keuangan perusahaan multinasional (Saudagaran, 2001). Beberapa manfaat lain dari standar akuntansi internasional menurut adalah bahwa suatu standar akuntansi internasional dapat membuka kemungkinan perbandingan laporan keuangan antarnegara, meningkatkan transparansi dalam pelaporan keuangan, mengurangi biaya informasi, dan menekan informasi yang tidak simetris (Ball, 2006). Terlebih lagi untuk negara berkembang, yang belum mampu untuk membuat standar akuntansi yang kuat, adopsi standar akuntansi internasional dapat memperkuat kemampuan kompetitif dalam pasar modal (Peavy \& Webster, 1990).

Tujuan penelitian ini adalah untuk mengetahui apakah BUMN Perkebunan perlu menerapkan PSAK adopsi IAS 41 Agriculture dan apakah penerapan tersebut dapat bermanfaat bagi pemegang kepentingan sehingga pelaporan keuangan akuntabel dan transparan; dengan demikian mendorong pengambilan keputusan yang lebih tepat. Penelitian diharapkan mampu untuk memberikan kontribusi dalam mengevaluasi dampak penerapan PSAK khususnya PSAK yang mengadopsi IAS 41 Agriculture pada BUMN Perkebunan di Indonesia.

\section{Tinjauan Pustaka}

Secara tradisional, perusahaan-perusahaan berbasis agrikultur menggunakan model biaya historis (historical cost model) dalam pelaporan keuangannya walaupun model biaya historis ini gagal menjadi ukuran salah satu aset terpenting perusahaan agrikultur yaitu aset biologis. Aset biologis tidak dapat secara tepat diukur menggunakan model biaya historis karena keunikan aset ini dengan karakteristik aset tersebut dapat berkembang dan bereproduksi secara alami (Argiles \& Slof, 2001). 
Selain itu, pengukuran menggunakan model biaya historis dinilai tidak dapat menangkap dan mencerminkan fenomena pasar yang berubah secara cepat dalam aset biologis (Cowan, 1972).

American Institute of Certified Public Accountants (AICPA) dan Canadian of Chartered Accountants (CICA) masing-masing pada 1985 dan 1986 menerbitkan pedoman akuntansi khusus untuk perusahaan-perusahaan berbasis agrikultur. Pedoman ini mensyaratkan pengukuran hasil panen dan hasil peternakan. Pada Februari 2001, International Accounting Standard Committee menerbitkan International Accounting Standard 41 yang merupakan standar akuntansi untuk perusahaanperusahaan berbasis agrikultur (IASC, 2001). Ciri utama dari standar akuntansi ini adalah penggunaan model nilai wajar (fair value model) untuk pengukuran aset biologisnya. Penggunaan model nilai wajar untuk aset biologisnya ini diyakini membuat IAS 41 merupakan standar akuntansi yang menyediakan a good conceptual framework (Argiles \& Slof, 2001). Penggunaan model nilai wajar ini didukung karena model ini dianggap mendorong transparansi dan pengambilan keputusan yang baik karena model nilai wajar ini mencerminkan kondisi pasar saat itu (Laux \& Leuz, 2009). Meskipun begitu, IAS 41 juga menimbulkan banyak kontroversi. Salah satu kontroversi tersebut adalah anggapan bahwa pendekatan yang digunakan IAS 41 too academic dan tidak fokus pada praktik pelaporan aset biologis (Herbohn \& Herbohn, 2006).

Lebih jauh, terkait penggunaan model nilai wajar beberapa penelitian meragukan keunggulan penggunaan model nilai wajar ini. Penggunaan nilai wajar lemah dari sisi keandalan informasi dan kemudahan untuk dipahami karena nilai wajar berpijak pada harga pasar arbitrer yang subjektif (Barlev \& Haddad, 2003; Penman, 2007; Benston, 2008). Penggunaan model nilai wajar memakan biaya dalam mendapatkan informasi harga wajar, terutama untuk entitas-entitas pelapor pada negaranegara berkembang (Elad, 2004). Selain itu, penggunaan nilai wajar menimbulkan volatilitas pada laba rugi yang dilaporkan entitas dan sering kali gagal untuk menangkap substansi ekonomi yang sebenarnya terjadi (Fargher, 2001; Penman, 2007). Gambar 1 menunjukkan perlakuan aset biologis.

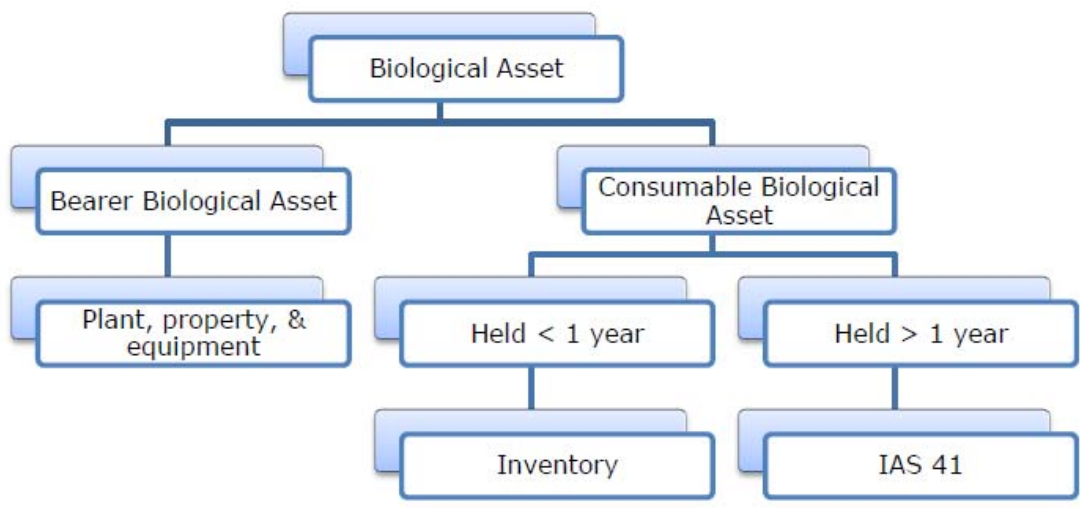

Gambar 1 Diagram Ilustrasi Perlakuan Aset Biologis

Berdasarkan kerangka dasar penyusunan dan penyajian laporan keuangan, terdapat empat karakteristik kualitatif utama dalam pelaporan keuangan agar laporan keuangan dapat dapat memberikan informasi yang berguna bagi pemakai. Empat karakteristik tersebut adalah dapat dipahami (understandability), relevan (relevance), keandalan (reliability), dapat diperbandingkan (comparability) (IASB, 2001). Empat karakteristik tersebut harus dicapai agar laporan keuangan dapat mencapai tujuannya. Akan tetapi, sering kali untuk memperoleh tingkat yang tinggi, suatu karakteristik harus mengorbankan karakteristik lain; misalnya beberapa pendapat mengatakan bahwa terdapat trade offs antara karakteristik keandalan dan relevan. Bahkan, beberapa pendapat mengatakan bahwa keandalan harus lebih tinggi daripada karakteristik relevan (Johnson, 2005). 
Informasi yang akan berguna bagi pengguna laporan keuangan adalah informasi yang dapat dipahami (IASB, 2001). Beberapa penelitian sebelumnya menyimpulkan bahwa penerapan mark-tomarket sulit dipahami baik oleh penyusun maupun pengguna laporan keuangan karena terlalu akademis dan akan sangat sulit dipahami lagi pada negara berkembang (Elad, 2004). Sementara dalam pengambilan keputusan informasi yang relevan diperlukan, yaitu informasi yang dapat memengaruhi pengambilan keputusan ekonomi dengan membantu mengevaluasi peristiwa masa lalu, masa kini, dan masa depan (IASB, 2001). Informasi yang relevan pada industri pertanian berfokus pada pengukuran yang secara tradisional menggunakan model biaya historis.

\section{METODE}

Populasi pada penelitian ini adalah seluruh BUMN berbasis perkebunan yang meliputi PTPN I sampai dengan PTPN XIV dan PT Rajawali Nusantara Indonesia. Sedangkan sampel yang akan diambil adalah sebagai berikut. Penekanan pada penelitian ini adalah tanaman tebu yang digolongkan sebagai tanaman semusim.

Tabel 1 Sampel Penelitian

\begin{tabular}{cll}
\hline No & Nama Perusahaan & \multicolumn{1}{c}{ Lokasi } \\
\hline 1 & PTPN II & Jakarta \\
2 & PTPN VII & Lampung \\
3 & PTPN VIII & Jawa Barat \\
4 & PTPN IX & Jawa Tengah \\
\hline
\end{tabular}

Metode pengumpulan data berupa tinjauan literatur yang diperoleh dari laman web, literatur keilmuan terkait, artikel yang dipublikasikan, dan laporan keuangan entitas. Kemudian survei menggunakan kuesioner berupa daftar pertanyaan yang telah disiapkan terlebih dahulu. Lalu wawancara yang dibagi menjadi dua yaitu penyusun laporan keuangan (dalam hal ini penyusun laporan keuangan perusahaan sampel) dan pemegang kepentingan yaitu pemerintah sebagai pemegang saham yang diwakili kementrian BUMN dan kementrian keuangan, auditor internal maupun eksternal, dan masyarakat diwakili akademisi. Selanjutnya observasi dilakukan on site pada masing-masing sampel perusahaan.

Validitas penelitian adalah kemampuan untuk mengukur sesuatu yang dimaksudkan untuk diukur. Penelitian menggunakan metode kualitatif sehingga validitas penelitan sangat penting. Untuk itu kuesioner berupa pertanyaan yang telah disiapkan terlebih dahulu dikirimkan kepada responden sebelum proses wawancara untuk memberikan waktu kepada responden mempersiapkan diri. Dengan demikian, proses wawancara diharapkan akan lebih fokus pada permasalahan dan pengumpulan data efektif dengan memperoleh hanya informasi yang diperlukan saja. Untuk menjaga validitas, pewawancara adalah orang yang kompeten dalam subjek penelitian dan mengerti tujuan penelitian. Proses wawancara direkam dengan seizin responden untuk menjaga ketepatan informasi yang diperoleh. Reliabilitas mengukur sampai mana tingkat penelitian bebas dari kesalahan. Dalam penelitian kualitatif, reliabilitas tidak sepenting validitas karena terdapat kemungkinan proses wawancara akan menghasilkan simpulan yang berbeda. Hasil wawancara akan dikonfirmasikan ulang kepada responden untuk disetujui agar hasil tersebut bebas dari salah pengertian (misinterpretation). Selanjutnya, untuk menjaga konsistensi jawaban, suatu permasalahan akan ditanyakan dengan menggunakan model pertanyaan yang berbeda. 


\section{HASIL DAN PEMBAHASAN}

Penelitian ini mengambil sampel tanaman tebu yang dikategorikan sebagai tanaman semusim. Tanaman ini merupakan tanaman utama yang dibudidayakan oleh PTPN. Siklus hidup tanaman tebu dimulai dari penanaman bibit. Bibit tebu yang ditanam umumnya berupa stek tanaman tebu berumur 5 sampai 7 bulan yang dipotong menjadi beberapa bagian. Setiap bagian mengandung 3 sampai 4 mata tunas. Bibit ini dapat digunakan untuk 3-4 kali masa tanam, bergantung dengan jumlah mata tunasnya.

\section{Pengakuan dan Pengukuran}

Menurut IAS 41, aset biologis harus diakui berdasarkan nilai awal yaitu sebesar nilai perolehannya. Menurut Ditjen Perkebunan, terdapat beberapa biaya dalam proses penanaman tebu yaitu biaya bibit, persiapan lahan, pengolahan tanah sampai dengan siap tanam, penanaman, dan keprasan atau penyulaman. Dalam implementasi IAS 41, biaya-biaya tersebut akan dikapitalisasi sebagai nilai perolehan awal tanaman tebu. Biaya-biaya tersebut akan mudah diidentifikasi karena dilaporkan melalui kegiatan-kegiatan yang terpisah. Selanjutnya, jika terdapat selisih antara biaya perolehan dengan nilai wajar bibit dikurangi perkiraan biaya untuk menjual, selisih tersebut harus diakui sebagi keuntungan atau kerugian di laporan laba rugi.

Pemeliharaan tanaman tebu dilakukan dengan kegiatan pemupukan dan pengairan. Sebanyak 85-90\% dari bobot segar sel-sel dan jaringan tanaman tinggi adalah air (Maynard dan Orcott, 1987). Noggle dan Frizt dalam Efendi (2009) menjelaskan beberapa fungsi air bagi tanaman di antaranya sebagai senyawa utama pembentuk protoplasma, sebagai senyawa pelarut bagi masuknya mineralmineral dari larutan tanah ke tanaman dan sebagai pelarut mineral nutrisi yang akan diangkut dari satu bagian sel ke bagian sel lain, maupun sebagai media terjadinya reaksi-reaksi metabolik. Oleh karena itu, kegiatan pengairan menjadi sebuah keharusan dan memiliki nilai manfaat untuk mempertahankan kelangsungan hidup tanaman tebu. Prinsip ini sesuai dengan prinsip kapitalisasi aset sehingga biaya atas kegiatan pengairan perlu dikapitalisasi ke dalam nilai aset biologis.

Berdasarkan pedoman akuntansi perkebunan berbasis IFRS, biaya pemupukan merupakan biaya proses yang dapat langsung diatribusikan pada tanaman tebu. Setiap biaya yang dikeluarkan untuk aktivitas pemupukan akan menambah nilai tanaman tebu. Akan tetapi, perlu diperhatikan lebih lanjut bahwa kapitalisasi ini sangat berhubungan dengan fase hidup tanaman tebu. Setiap varietas tebu memiliki masa tumbuh optimal yang berbeda-beda. Dalam tahap pertumbuhan dari bibit hingga masa optimal ini, rendemen tanaman tebu memiliki potensi peningkatan. Sedangkan setelah melewati masa tersebut, rendemennya akan cenderung mengalami penurunan terkait adanya penuaan tanaman. Nilai rendemen ini sangat penting dan berpengaruh terhadap jumlah produk agrikultur yang dihasilkan berupa gula pasir.

Dalam perjalanannya tanaman tebu dapat mengalami kematian dengan berbagai sebab misalnya kematian secara alami karena serangan hama, kondisi tanah, maupun cuaca yang tidak mendukung. Proses identifikasi tanaman tebu yang mati akan sulit jika dihitung secara satuan karena begitu luasnya lahan tebu dan amat rapat jarak setiap tanaman. Oleh karena itu, identifikasi ini dapat dilakukan dengan melihat pertumbuhan sekelompok tanaman tebu pada petak tertentu. Jika tanaman tebu sudah mati akan tampak tanda-tanda seperti daun tanaman menguning dan batang tebu menjadi kering. Atas kematian tanaman tebu tersebut, perusahaan harus mendebit adanya rugi karena kehilangan masa mafaat dari tanaman tersebut. Sedangkan pada sisi kredit perusahaan harus memasukkan nilai aset biologis yang hilang pada saat diidentifikasi adanya kematian tanaman tebu.

IAS 41 mewajibkan penggunaan nilai wajar untuk produk agrikultur yang baru saja dipanen. Lefter dan Roman (2007) berpendapat bahwa hal ini dilakukan agar proses transformasi yang ada bisa 
segera terwakili di laporan keuangan sehingga membantu investor dalam mengestimasi keuntungan ekonomis pada masa depan. Penggunaan nilai wajar bisa diterapkan dengan mudah pada produk agrikultur tebu yang baru dipanen. Hal ini karena terdapat cukup banyak pasar untuk tebu yang baru saja dipanen. Pasar yang terjadi antara penjual tebu (petani) dan pembeli tebu (pabrik gula) dapat dikatakan pasar aktif karena pertama, barang yang dijual homogeny (tebu); kedua, penjual dan pembeli yang berkeinginan melakukan transaksi dapat dengan mudah ditemukan karena umlah mereka lebih dari satu sehingga tidak ada pihak yang bisa memengaruhi harga pasar secara dominan; ketiga, harga tanaman tebu dapat diketahui publik dengan mudah.

Saat panen bisa saja terjadi selisih antara nilai kapitalisasi terakhir dan nilai wajar saat titik panen dikurangi perkiraan biaya untuk menjual. Selisih tersebut harus diakui sebagai keuntungan atau kerugian dan dilaporkan dalam laba rugi. Misalnya saat 31 Desember 2012 perusahaan mencatat nilai tanaman-tanaman tebu (consumable biological assets) adalah Rp1.000.000,00. Saat panen, nilai wajar dikurangi biaya menjual tanaman tadi menjadi Rp1.200.000,00. Maka entitas harus mengakui Rp200.000,00 sebagai keuntungan dan melaporkannya dalam laporan laba rugi. Nilai Rp1.200.000,00 selanjutnya dianggap sebagai biaya perolehan persediaan.

\section{Penyajian dan Pengungkapan}

Pengklasifikasian tebu siap panen sebagai persediaan seperti yang dilakukan oleh PTPN II dan Pedoman Penyajian dan PLK Emiten atau Perusahaan Publik Industri Perkebunan sesuai dengan Aryanto (2011). Consumable biological assets yang umurnya kurang dari satu tahun sebaiknya diperlakukan sama dengan persediaan; jika terjadi transformasi biologis sebaiknya diperlakukan sebagai barang dalam proses (Aryanto, 2011). Namun aset biologis yang berumur kurang dari satu tahun lebih tepat jika diklasifikasikan sebagai aset biologis, bukan sebagai persediaan. Alasan pengklasifikasian tersebut adalah adanya transformasi biologis pada aset tersebut. Transformasi tersebut berkaitan dengan proses accretion (pertambahan), yang pendapatan bisa diperoleh sepanjang aset tersebut tumbuh (Aryanto, 2011).

\section{SIMPULAN}

Berdasarkan penelitian dapat disimpulkan bahwa pengungkapan aset biologis tanaman tebu sebaiknya dikelompokkan berdasarkan lokasi jika entitas mempunyai tebu di beberapa lokasi yang berbeda dengan karakteristik biaya dan kesuburan tanah yang berbeda-beda. Lefter dan Roman (2007) menyatakan sebaiknya aset biologis dibagi berdasarkan sudut pandang lokasi jika perbedaan lokasi menyebabkan perbedaan karakteristik dan perbedaan biaya. Terkait perkebunan tebu, keuntungan atau kerugian akibat perubahan nilai wajar aset biologis dikurangi biaya menjual memang lebih tepat jika dilaporkan dalam laba rugi. Hal ini karena umur tanaman tebu yang relatif pendek (hanya 8-14 bulan), sehingga keuntungan akibat revaluasi akan segera terealisasi beberapa bulan kemudian. Pengakuan keuntungan atau kerugian setelah revaluasi akan membuat laporan keuangan makin relevan dan mewakili keadaan yang sesungguhnya. 


\section{DAFTAR PUSTAKA}

Argiles, J., \& Slof, E. (2001). New opportunities for farm accounting. The European Accounting Review, 10(2), 361-383.

Aryanto, Y. H. (2011). Theoretical Failure of IAS 41. Diakses dari http://papers.ssrn.com/sol3/papers.cfm?abstract_id=1808413

Ball, R. (2006). International Financial Reporting Standards (IFRS): pros and cons for investors. Accounting and Business Research, 5-27.

Barlev, B., \& Haddad, J. (2003). Fair value accounting and management of the firm. Critical Perspectives on Accounting, 14(4), 383-415.

Benston, G. (2008). The shortcomings of fair-value accounting described in SFAS 157. Journal of Accounting and Public Policy, 27(2), 101-114.

Cowan, T. (1972). Fact and fiction in farm accounting. Accountant's Journal , 130-139.

Elad, C. (2004). Fair value accounting in the agricultural sector: Some implications for international accounting harmonisation. European Accounting Review, 13(4), 621-641.

Fargher, N. (2001). Management perceptions of fair-value accounting for all financial instruments. Australian Accounting Review, 11(2), 62-72.

Herbohn, K., \& Herbohn, J. (2006). International Accounting Standards (IAS) 41: what are the implications for reporting forest assets. Small-scale Forest Economics, Management and Policy, 5(2), 175-189.

IASB. (2001). Framework for the Preparation and Presentation of Financial Statements. International Accounting Standards Board.

IASB. (2009). International Accounting Standard 41 Agriculture. Diakses dari http://ec.europa.eu/internal_market/accounting/docs/ac/ias41_en.pdf

IASC. (2001). International Accounting Standard 41: Agriculture. International Accounting Standards Committee.

Insitut Akuntan Publik Indonesia (2002). Pedoman Penyajian dan Pengungkapan Laporan Keuangan Emiten atau Perusahaan Publik Industri Perkebunan. Diakses dari http://www.iapi.or.id/member_area/PLK/Industri\%20Perkebunan.pdf

Johnson, T. L. (2005, February). Relevance and reliability. The FASB Report.

Laux, C., \& Leuz, C. (2009). The crisis of fair-value accounting: making sense of the recent debate. Accounting, Organizations and Society, 34(6-7), 826-834.

Lefter, V., \& Roman, C. (2007). The fiscal control and the financial jurisdiction - components of the competitive management. Theoretical and Applied Economics, 11(11), 53-58. 
Maynard, G. H., \& Orcott, D. M. (1987). The Physiology of Plants Under Stress. New York: John Willey and Sons.

Peavy, D., \& Webster, S. (1990). Is GAAP the gap to international market? Management Accounting, 72, 31-35.

Pedoman Akuntansi BUMN perkebunan berbasis IFRS. http://docs.rni.co.id/trainsite/Lists/Announcements/Attachments/8/Pedoman\%20Akuntansi\%2 0Perkebunan\%20BUMN\%20-\%2005122011.pdf

Penman, S. H. (2007). Financial reporting quality: is fair value a plus or a minus? Accounting and Business Research. Special issue: International Accounting Policy Forum, 33-44.

PT Perkebunan Nusantara II (2012). Laporan Tahunan PTPN II 2011. Diakses dari http://ptpn2.com/AnnualReport2011.pdf

Saudagaran, S. (2001). International Accounting: A User Perspective. South Western College. 